\title{
Airway Pressure and Respiratory Mechanics Variability with Different Body Positions in Mechanically Ven- tilated Critical Care Patients: A Prospective Comparative Clinical Study
}

\author{
Alaa Ali M. Elzohry ${ }^{1 *}$, Eman Fadl Abd El Khalik², Al Shimaa Ismael Roushdy ${ }^{3}$, Marwa Mohammad Abdelbaky ${ }^{4}$ \\ ${ }^{1}$ Lecturer of Anesthesia, ICU and Pain Relief, South Egypt Cancer Institute, Assiut University, Egypt \\ ${ }^{2}$ Lecturer of Medical-Surgical Nursing, Faculty of Nursing, Minia University, Egypt \\ ${ }^{3}$ Lecturer of Anesthesiology and Intensive Care, Faculty of Medicine, Minia University, Egypt \\ ${ }^{4}$ Lecturer in Medical-Surgical Nursing (Critical Care Nursing), Faculty of Nursing, Minia University, Egypt \\ Correspondence to: Alaa Ali M. Elzohry, Department of Anesthesia, ICU and Pain Relief, South Egypt Cancer Institute, Assiut University, Arab Republic of Egypt. \\ Phone: +20-01007356462,+20-088-2060010; Email: alaa.zohiry@ hotmail.com \\ Received date: November 12, 2020; Accepted date: November 24, 2020; Published date: December 2, 2020 \\ Citation: Elzohry AAM, Abd El Khalik EF, Ismael Roushdy AS, et al. (2020) Airway Pressure and Respiratory Mechanics Variability with Different Body Positions in \\ Mechanically Ventilated Critical Care Patients: A Prospective Comparative Clinical Study. J Clin Anesthes Res 1(1): pp. 1-6. \\ Copyright: (C2020 Elzohry AAM, et al. This is an open-access article distributed under the terms of the Creative Commons Attribution License, which permits \\ unrestricted use, distribution and reproduction in any medium, provided the original author and source are credited.
}

\section{ABSTRACT}

Aim: This prospective comparative study aimed to investigate the effect of various body positions on changes of respiratory parameters mostly; the TV, oxygen saturation, airway pressure, and endotracheal tube cuff pressure in mechanically ventilated critical care patients.

Background: Many patients who are admitted to the critical care unit require intubation and invasive mechanical ventilation for many reasons such as major trauma, medical causes, or post-operative major surgeries. Changing a patient's position in the critical care unit is very important for the following benefits; to break through the routine monotonic delivery of mechanical ventilation, to favor the clearance of respiratory secretions, the prevention of pressure sores and ventilator acquired pneumonia, and finally the improvement in lung volume and oxygenation Methods: A prospective, comparative study was carried out on 210 patients of both gender, aged between 2170 years old admitted to ICU due to many reasons. After stabilization of patient condition and connection of monitors' cables, supine position or semi setting position was chosen and this was documented in the patient's chart. All patients were sedated to prevent them from breathing against the machine which causes the ETT cuff pressure and mean airway pressure to rise. Fentanyl sedation drug (Loading dose: $1-2 \mathrm{mic} / \mathrm{kg} / \mathrm{hour}$ infused gradually. Maintenance dose: $1-4 \mathrm{mic} / \mathrm{kg} / \mathrm{hour}$ ) using continuous intravenous infusion typically in combination with Midazolam sedation (0.05- $0.2 \mathrm{mg} / \mathrm{kg} /$ hour). The following parameters were recorded; tidal volume, mean airway pressure, $\mathrm{PO}_{2} / \mathrm{FIO}_{2}$, and ETT cuff pressure.

Results: Our results show that about (58.1\%) were male and (41.9\%) were female. Concerning age, their mean was between ( $40.6 \pm 8.9$ ) years. Regarding diagnosis $(50.5 \%)$ of patients were admitted with major trauma, (31.9\%) due to medical causes, and (17.6\%) admitted due to major chest and abdominal surgeries. The patient's mean heart rate was $(93.6 \pm 7.5) \mathrm{b} / \mathrm{m}$ and the Mean Arterial Pressure was $(67.7 \pm 0.6)^{\circ} \mathrm{C}$. Tables the Description, SOP2, Mean airway, and ETT cuff pressure of each body position in the study with the highest $\mathrm{SPO}_{2} 98 \%$ and cuff pressure $19.2+41$ in the prone position. The position checklist is illustrated in Table and Figure. The highest TV $\left(520 \mathrm{ml}\right.$ ) and $\mathrm{PO}_{2} / \mathrm{FIO}_{2}$ ratio (410) were in prone poison and the lowest was in Lower Fowler position (460 $\mathrm{ml}$ and 320) respectively. Regarding outcome and ICU stay which were the best in both semi setting and prone position.

Conclusion: Supine position (lying flat) or lateral position do not seem beneficial for critically ill patients in terms of respiratory mechanics. The semi-sitting position (with thorax angulation $=30^{\circ}$ from the horizontal plane) is associated with improvement of $\mathrm{PO}_{2} / \mathrm{FlO}_{2}$, oxygenation, and tidal volume, and the effects of prone position on respiratory mechanics are very beneficial and this reflected on patient outcome and short ICU length of stay.

\section{Keywords:}

ICU, Airway pressure, Prone position, Mechanical ventilation, Supine position, Sedation

\section{Introduction}

Many patients who are admitted to the critical care unit require intubation and invasive mechanical ventilation for many reasons such as major trauma, medical causes or post-operative major surgeries. The early stage of management of invasive mechanical ventilation usually delivered in a semi setting or supine position with or without sedation and changing position is very important for the following benefits; to break through the routine monotonic delivery of mechanical ventilation, to favor the clearance of respiratory secretions, the prevention of pressure sores and ventilator acquired pneumonia, and finally the improvement in lung volume and oxygenation [1-4].

Additionally, there are significant circulatory and respiratory changes with changes in body position in both awake and 
sedated patients. These changes may affect the blood-gas exchange and cerebral hemodynamic which in turn affect supply to CNS and peripheral nerves [5].

Positioning change for critical patients is one of the routine daily interventions in ICU that are applied to prevent the above-mentioned complications and optimize the respiratory parameters as tidal volume, FRC, and oxygen saturation. Body position change affected these parameters which should be readjusted and monitored carefully [6-7].

The pattern and mode of the respiratory cycle may be determined by upper airway characteristics and by the synchronism between upper airway muscles and respiratory muscles [8]. Mean airway pressure typically refers to the mean pressure applied during positive-pressure mechanical ventilation. Mean airway pressure correlates with alveolar ventilation, arterial oxygenation, hemodynamic performance, and barotrauma [9].

Endotracheal tube cuff pressure presents the relation between the trachea and the tube cuff which prevents any air leak and aspiration. ETT cuff pressure should be regularly monitored using a cuff pressure manometer which should be the standard of care for each ETT inserted [10].

This prospective comparative study aimed to investigate the effect of various body positions on changes of respiratory parameters mostly; the TV, oxygen saturation, airway pressure, and endotracheal tube cuff pressure in mechanically ventilated critical care patients.

\section{Methodology}

This is a comparative study that was carried out in ICU at Minia University hospital of Egypt the period from (June 2018 to June 2020), Written informed consent was obtained by the researchers from the patients after explaining the aim of the study and confidentiality of data, privacy, voluntary participation and right to refuse to participate in the study were informed to them by the researchers through personal communication, and a pilot study was done on 21 of ICU patients to test the feasibility of the study and applicability of the tool and there are no modifications done.

The inclusion criteria included all critical care patients, aged between (18-70 years), of both genders (male and female), orally intubated and attached with positive pressure mechanical ventilation. The patient should be under sedation according to the ICU regimen with stable hemodynamic circulation.

210 patients were enrolled for 2 years. The following data were collected by the researchers who were blind to the study design as patient's age, sex, diagnosis, and medical history also patient's position parameters as type, duration, and ICU length of stay. The validity of the study: was tested by a jury panel of 7 experts in the field of anesthesia and surgery and the reliability: was done using Cronbach's alpha test.

After stabilization of patient condition and connection of monitors' cables, supine position or semi setting position was

Table 1: Demographic and surgical data of the studded sample (No. 210). chosen and this was documented in the patient's chart. All patients were sedated to prevent them from breathing against the machine which causes the ETT cuff pressure and mean airway pressure to rise. Fentanyl sedation drug (Loading dose: 1-2 mic/kg/ hour infused gradually. Maintenance dose: 1-4 $\mathrm{mic} / \mathrm{kg} /$ hour) using continuous intravenous infusion typically in combination with Midazolam sedation $(0.05-0.2 \mathrm{mg} / \mathrm{kg} /$ hour). The following parameters were recorded; tidal volume, mean airway pressure, $\mathrm{PO}_{2} / \mathrm{FIO}_{2}$, and ETT cuff pressure.

Then the patient started to be turned to the second routine ICU position change which is the dorsal recumbent position. After spending 20 minutes in the previous position and documented in the patient's chart the left the patients to spend the rest of the two hours in position. At the end of the two hours, the same parameters were recorded.

After that patient was turned to the Third position change which is the Lower Fowler's position for two hours then the same parameters were recorded. All Patients of the study (210) were turned to 6 different positions according to the ICU routine every 2 hours by the researchers and the assistance of the ICU nurses to ensure that every patient turned to the optimal position and suitable body alignment to not harm the patients during positioning change. The 6 applied body positions included in the study as shown in the following table At the end of the study, the duration of ICU length of stay and patients outcomes were recorded and analyzed.

\section{Statistical analysis}

Data entry and analysis were done using SPSS version 22 ${ }^{\circledR}$ (Statistical Package for Social Science). Data were presented as number, percentage, mean \pm standard deviation. A Chisquare test was used to compare qualitative variables. MannWhitney test was used to compare quantitative variables between the studied groups. Wilcoxon Signed Rank test was done to compare every two times in the same group. P-value is considered statistically significant when $\mathrm{P}<0.05$.

\section{Results}

Our results show that about (58.1\%) were male and $(41.9 \%)$ were female. About age, their mean was between $(40.6 \pm 8.9)$ years. Regarding diagnosis (50.5\%) of patients were admitted with major trauma, (31.9\%) due to medical causes, and (17.6\%) admitted due to major chest and abdominal surgeries. The patient's mean heart rate was $(93.6 \pm 7.5) \mathrm{b} / \mathrm{m}$ and the Mean Arterial Pressure was $(67.7 \pm 0.6)^{\circ} \mathrm{C}$ (Table 1). Table 2 shows Description, $\mathrm{SOP}_{2}$, Mean airway and ETT cuff pressure of each body position in the study with the highest SPO2 98\% and cuff pressure $19.2+41$ in the prone position. Position checklist is illustrated in (table 3 ) and (Figure 1). The highest TV $(520 \mathrm{ml})$ and $\mathrm{PO}_{2} / \mathrm{FIO}_{2}$ ratio (410) were in prone poison and the lowest was in Lower Fowler position (460 $\mathrm{ml}$ and 320) respectively (Figure 2). Regarding outcome and ICU stay which were the best in both semi setting and prone position (Figure 3 ).

\begin{tabular}{|l|l|l|}
\hline Personal data & No. & \multicolumn{2}{l|}{} \\
\hline Sex & \multicolumn{2}{|l|}{} \\
\hline Male & 121 & 58.1 \\
\hline
\end{tabular}




\begin{tabular}{|c|c|c|}
\hline Female & 89 & 41.9 \\
\hline \multicolumn{3}{|l|}{ Age / Year } \\
\hline $25-35$ & 69 & 33.3 \\
\hline 36- 45 & 85 & 40 \\
\hline 46- 55 & 56 & 26.7 \\
\hline Mean \pm SD & \multicolumn{2}{|l|}{$40.6 \pm 8.9$} \\
\hline \multicolumn{3}{|l|}{ Medical data } \\
\hline \multicolumn{3}{|l|}{ Diagnosis } \\
\hline Trauma patients & 106 & 50.5 \\
\hline Medical causes (DM-stroke-poisoning) & 66 & 31.9 \\
\hline Major postoperative & 38 & 17.6 \\
\hline \multicolumn{3}{|l|}{ Baseline Oxygen Saturation } \\
\hline 90- 94 & 70 & 33.3 \\
\hline 95- 100 & 140 & 66.7 \\
\hline Mean \pm SD & \multicolumn{2}{|l|}{$95.1 \pm 2.3$} \\
\hline Heart Rate $(b / m)$ (Mean \pm SD) & \multicolumn{2}{|l|}{$93.6 \pm 7.5$} \\
\hline Mean Arterial Pressure (Mean \pm SD) & \multicolumn{2}{|l|}{$67.7 \pm 0.6$} \\
\hline
\end{tabular}

Table 2: Description, $\mathrm{SOP}_{2}$, Mean airway and ETT cuff pressure of each body position in the study.

\begin{tabular}{|c|c|c|c|c|}
\hline Position & How of applied Position & $\mathrm{SPO}_{2}$ & Mean Airway pressure & Cuff pressure adjustment \\
\hline Supine & $\begin{array}{l}\text { Dorsal recumbent body } \\
\text { position with the backrest of } \\
\text { the bed at zero levels and the } \\
\text { head in a neutral alignment of } \\
\text { body positions }\end{array}$ & $98 \%$ & $15 \pm(3.9)$ & $\begin{array}{l}\text { Cuff pressure adjusted } \\
\text { to: }\left(20-30 \mathrm{~cm} \mathrm{H}_{2} \mathrm{O}\right) \text { using } \\
\text { manometer }\end{array}$ \\
\hline Lower fowler & $\begin{array}{l}\text { Lower fowler position with the } \\
\text { back elevated at } 30^{\circ} \text { degree }\end{array}$ & $95 \%$ & $18 \pm(3.15)$ & $\begin{array}{l}\text { Cuff pressure adjusted } \\
\text { to: }\left(20-30 \mathrm{~cm} \mathrm{H}_{2} \mathrm{O}\right) \text { using } \\
\text { manometer }\end{array}$ \\
\hline High fowler & $\begin{array}{l}\text { High fowler position with } 45^{\circ} \\
\text { back and head up }\end{array}$ & $97 \%$ & $15 \pm(4.02)$ & $\begin{array}{l}\text { Cuff pressure adjusted } \\
\text { to: }\left(20-30 \mathrm{~cm} \mathrm{H}_{2} \mathrm{O}\right) \text { using } \\
\text { manometer }\end{array}$ \\
\hline Lateral & $\begin{array}{l}\text { Left lateral rotation of the } \\
\text { body and head with } 30^{\circ} \text { head } \\
\text { up }\end{array}$ & $96 \%$ & $15 \pm(4.02)$ & $\begin{array}{l}\text { Cuff pressure adjusted } \\
\text { to: }\left(20-30 \mathrm{~cm} \mathrm{H}_{2} \mathrm{O}\right) \text { using } \\
\text { manometer }\end{array}$ \\
\hline Semi setting & $\begin{array}{l}\text { Right lateral rotation of the } \\
\text { body and head with } 30^{\circ} \text { head } \\
\text { up }\end{array}$ & $95 \%$ & $19 \pm(4.24)$ & $\begin{array}{l}\text { Cuff pressure adjusted } \\
\text { to: }\left(20-30 \mathrm{~cm} \mathrm{H}_{2} \mathrm{O}\right) \text { using } \\
\text { manometer }\end{array}$ \\
\hline Prone position & $\begin{array}{l}\text { Prone position with the head } \\
\text { facing the bed linen and at one } \\
\text { side position }\end{array}$ & $98 \%$ & $19 \pm(4.24)$ & $\begin{array}{l}\text { Cuff pressure adjusted } \\
\text { to: }\left(20-30 \mathrm{~cm} \mathrm{H}_{2} \mathrm{O}\right) \text { using } \\
\text { manometer }\end{array}$ \\
\hline
\end{tabular}

Table 3: Positioning checklist.

\begin{tabular}{|l|l|l|}
\hline A-Airway & Endotracheal tube/LMA & Patent and in the correct position \\
\hline B-Breathing & Ventilation Auscultation Monitoring & $\begin{array}{l}\text { Pulmonary compliance satisfactory Both axillae } \\
\mathrm{SaO}_{2} \text { Capnograph trace and shape }\end{array}$ \\
\hline C-Circulation & Monitoring & $\begin{array}{l}\mathrm{HR} / \mathrm{BP} / \text { ECG still functioning and readings stable } \\
\text { Intravascular lines All still in-situ, patent and } \\
\text { accessible }\end{array}$ \\
\hline D-Disability/Neurology & Eyes Neurovascular & $\begin{array}{l}\text { Closed and protected Padded vulnerable areas } \\
\text { and avoidance of excessive passive stretch }\end{array}$ \\
\hline
\end{tabular}




\begin{tabular}{|l|l|l|}
\hline E-Exposure & $\begin{array}{l}\text { All cables, catheters, and electrode Checked } \\
\text { and removed from the patient/operating table } \\
\text { interface }\end{array}$ & $\begin{array}{l}\text { Access Maintain access for review of at-risk areas } \\
\text { if possible }\end{array}$ \\
\hline
\end{tabular}

Table 4: The correlation (R) between different positions and TV, MAP and ETT cuffed pressure.

\begin{tabular}{|l|l|l|l|}
\hline Variable & $\begin{array}{l}\mathbf{R} \\
\text { Mean airway pressure }\end{array}$ & $\begin{array}{l}\mathbf{R} \\
\text { Tidal volume }\end{array}$ & $\begin{array}{l}\mathbf{R} \\
\text { ETT cuffed pressure }\end{array}$ \\
\hline Supine position & 0.07 & 0.09 & 0.08 \\
\hline Lateral & 0.061 & 0.045 & 0.041 \\
\hline Semi setting & 0.133 & 0.170 & 0.124 \\
\hline Lower fowler & 0.009 & 0.011 & 0.071 \\
\hline High fowler & 0.843 & 0.812 & 0.898 \\
\hline Prone position & $0.187^{* *}$ & $0.188^{* *}$ & $0.179^{* *}$ \\
\hline
\end{tabular}
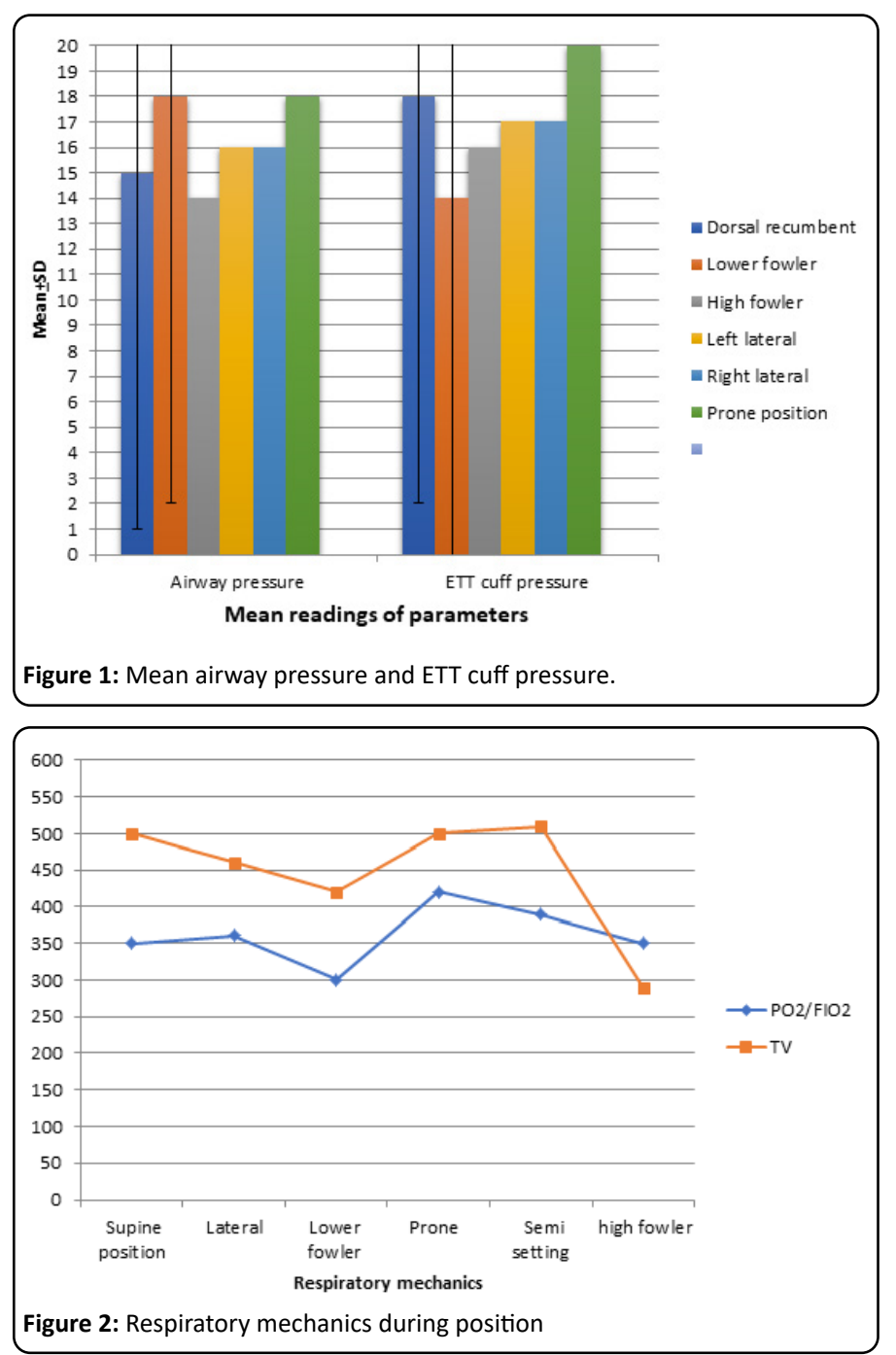

\section{Discussion}

The present study was done on 210 patients within mechanically ventilated patients due to different diagnoses in different positions, to investigate the airway pressure and respiratory mechanics as tidal volume and oxygen saturation. The ventilation parameters were found optimum in prone position and semi setting position with minimum MV and ICU duration but ETT cuff pressure is higher than other positions.

These results were found as previous studies of more than

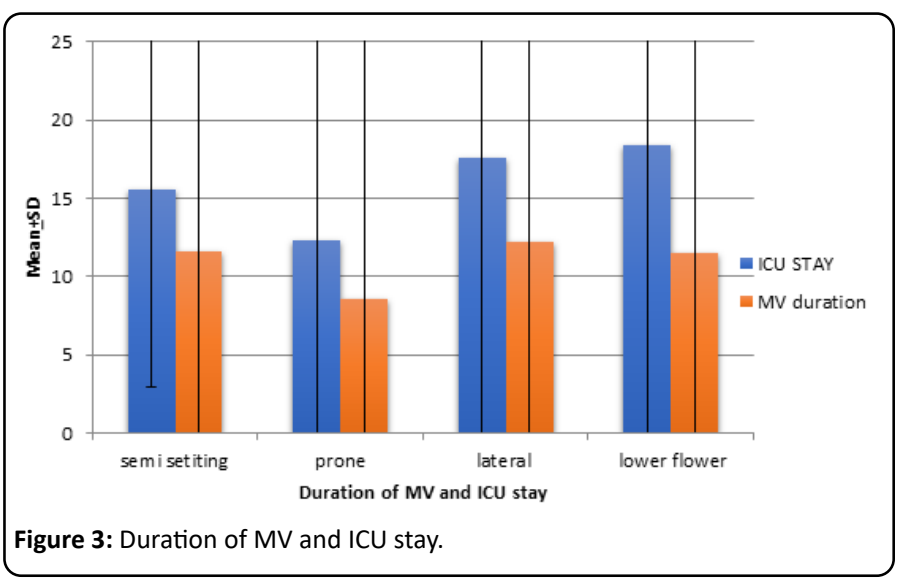

800 participants by Lee and Letvin who found the duration of mechanical ventilation was reported less than other positions. However, the point estimate amounted to less than a half-day and cannot be considered a major patient-centered benefit. Such data are made complicated to interpret by differential patient mortality between groups, which will affect time data such as duration of mechanical ventilation and length of stay [11-12].

This was explained by the physiological effects of prone positioning in patients with severe lung injury manifest as improvements in oxygenation and respiratory mechanics. There may also be a reduction in mechanical factors associated with VALI, such as an inhomogeneous distribution of pleural pressure (Ppl), alveolar inflation and ventilation, an increase in lung volume and reduction in atelectatic lung regions and, finally, an improvement in the clearance of secretions. Since the majority of animal and human studies investigating the physiological effects of prone positioning refer to acute ARDS, the considerations discussed later apply only to the early stages of the syndrome [13-15].

Tracheal tube displacement or increased ETT cuff pressure, which might be considered a natural consequence of moving patients from supine to prone position and back, showed differing results across studies, with moderate statistical heterogeneity. For example, the short-term (24-hour) study of Leal 1997 reported 50\% increased ETT cuff pressure, whereas Chan (2007), which utilized at least 72 hours of proning per participant, reported a zero rate of displacement [16-17]. 
These disadvantages of prone posion and the overall risk ratio were 1.09 and were statistically insignificant. However, a clear increase in the risk of tracheal tube obstruction was evident. Such obstruction might result from increased inspissated secretions or from kinking of the tracheal tube in the face-down participant. The risk ratio for this complication was 1.78 and was statistically significant ( $P$-value=0.003) [18].

The nature and magnitude of the effects of prone position on respiratory mechanics should not explain per se the effects of proning on mortality in severe ARDS patients. Two reasons may explain this hypothesis. The first is that the resolution of the methods to measure respiratory mechanics may miss important regional effects, like stress and strain homogenization, that is a major contributor to ventilator-induced lung injury prevention and hence patient outcome [19-20].

Critically ill patients can be manually turned laterally during the prone position maneuver for a few minutes or left longer in lateral position for preventing pressure sores or treating atelectasis. Modern ICU beds propose an automatic rotation of the patients at a given inclination and more advanced devices provide a continuous lateral rotation with a steep lateral position. In the lateral position, it is expected that dependent lung EELV decreases, airway resistance and lung and chest wall elastance increase with opposite findings to the non-dependent lung as compared to supine [21-22].

Regarding changes from sitting to supine the Pressure-Volume (PV) curve of the chest wall is going to change while that of the lungs does not that much. Therefore, the PV curve of the respiratory system follows that of the chest wall during the position change. The relaxation (or resting) volume of the chest wall goes down from $55 \%$ to $35 \%$ of the Vital Capacity (VC) and that of the respiratory system from $35 \%$ to $20 \%$ VC between upright and supine position [23].

The present study was in line with Ziyaeifard, et al. in a study that investigated the effect of different patient positions on endotracheal tube cuff pressure after adult cardiac surgery, they found (43.6\%) of the measurements were greater than the upper target limit $\left(30 \mathrm{~cm} \mathrm{H}_{2} \mathrm{O}\right)$ after positioning change. Letvin $A$, et al. and Sharifi, et al. were in line with the present study and found that the majority of the orally intubated patients with an ETT their cuff pressure measurements were higher than the recommended range (above $30 \mathrm{~cm} \mathrm{H}_{2} \mathrm{O}$ ) after changing the body position [24-26].

On the other hand, the present study found that more than half of the studded sample their ETT cuff pressure was lower than normal (below $20 \mathrm{~cm} \mathrm{H}_{2} \mathrm{O}$ ) when they were in right lateral rotation of the body and head. The present finding was in line with Alcan et al., (19) who demonstrated a reduction in the ETT cuff pressure after changing position to lateral position. Also, the same author emphasized that high sedation doses is one of the most important things that lead to a significant decrease in the ETT cuff pressure (below $20 \mathrm{~cm} \mathrm{H}_{2}$ ) and it will increase after sedation withdrawal [27-45].

\section{Conclusion}

Supine position (lying flat) or lateral position do not seem beneficial for critically ill patients in terms of respiratory mechanics. The semi-sitting position (with thorax angulation $=30^{\circ}$ from the horizontal plane) is associated with improvement of
$\mathrm{PO}_{2} / \mathrm{FIO}_{2}$, oxygenation and tidal volume, and the effects of prone position on respiratory mechanics is very beneficial and this reflected on patient outcome and short ICU length of stay. The study had limitations as it needs to be repeated on a larger sample size with different parameters and mechanics to get more solid results.

\section{Funding}

The authors have no sources of funding to declare for this manuscript.

\section{Conflicts of Interest:}

The authors declare no conflicts of interest.

\section{References}

1. Dash HH, Chavali S (2018) Management of traumatic brain injury patients. Korean J Anesthesiol 71(1): pp. 12-21

2. Rahmani F, Soleimanpour H, Zeynali A, et al. (2017) Comparison of tracheal tube cuff pressure with two techniques: fixed volume versus pilot balloon palpation. J CardiovascThorac Res 9(4): pp. 196-199.

3. Thomas PJ, Paratz JD, Lipman J, et al. (2007) Lateral positioning of ventilated intensive care patients: a study of oxygenation, respiratory mechanics, hemodynamics, and adverse events. Heart Lung 36(1): pp. 277-286.

4. Riad Z, Mezidi M, Subtil F, et al. (2018) Short-term Effects of the Prone Positioning Manoeuver on Lung and Chest Wall Mechanics in ARDS Patients. Am J Respir Crit Care Med 197(5): pp. 1355-1358.

5. Cornejo RA, Diaz JC, Tobar EA, et al. Effects of prone positioning on lung protection in patients with acute respiratory distress syndrome. Am J Respir Crit Care Med 188(4): pp. 440-448.

6. Gattinoni L, Pesenti A, Carlesso E (2013) Body position changes redistribute lung computed-tomographic density in patients with acute respiratory failure: impact and clinical fallout through the following 20 years. Intensive Care Med 39(11): pp. 1909-12.

7. Sanaie S, Rahmani F, Chokhachian S, et al. (2019) Comparison of tracheal tube cuff pressure with two technique: fixed volume and minimal leak test techniques. J CardiovascThorac Res 11(1): pp. 48-52.

8. Hughes CG, McGrane S, Pandharipande PP (2012) Sedation in the intensive care setting." Clinical pharmacology: advances and applications 4(1): pp: 53-63.

9. Reade MC, Delaney A, Bailey MJ, et al. (2010) Prospective meta-analysis using individual patient data in intensive care medicine. Intensive Care Medicine 36(1): pp. 11-21.

10. Slutsky AS, Ranieri VM (2013) Ventilator-induced lung injury. New England Journal of Medicine 369(22): 2126-2136.

11. Lee JM, Bae W, Lee $Y$ J, et al. (2014) The efficacy and safety of prone positional ventilation in acute respiratory distress syndrome: updated study-level meta-analysis of 11 randomized controlled trials. Critical Care Medicine 42(5): pp. 1252-1262.

12. Oliven A, O'Hearn DJ, Boudewyns A, Odeh M, De Backer $W$, van de Heyning P, Smith PL, Eisele DW, Allan L, Schneider $H$, Testerman R, Schwartz AR: Upper airway response to electrical stimulation of the genioglossus in obstructive sleep apnea. J Appl Physiol 2013; 95: 2023-2029.

13. National Pressure Ulcer Advisory Panel and European 
Pressure Ulcer Advisory Panel. Pressure ulcer prevention recommendations. Prevention and treatment of pressure ulcers: clinical practice guideline 2009. http:// www.guideline.gov

14. Bassi GL, Bertral R, Martí JD, et al. (2012) New insights in positioning tracheally intubated and mechanically ventilated patients. Clinical Pulmonary Medicine 19(4): pp. 174-82.

15. Porto EF, Castro AAM, Leite JRO,et al. (2008) Comparative analysis of respiratory system compliance in three different positions (lateral, supine and sitting) of patients on long-term invasive mechanical ventilation. Revista Brasileira de T erapia Intensiva 20(3): pp. 213-219.

16. Ledwith M, Bloom S, Maloney-Wilensky E, et al. (2010) Effect of body position on cerebral oxygenation and physiologic parameters in patients with acute neurological conditions. J Neurosci Nurs 42(5): pp. 280-287.

17. Nseir S, Brisson $\mathrm{H}$, Marquette $\mathrm{CH}$, et al. (2009) Variations in endotracheal cuff pressure in intubated critically ill patients: prevalence and risk factors. Eur J Anaesthesiol 26(3): pp. 229-34.

18. Ziyaeifard M, Ferasatkish R, Alizadehasl A, et al. (2017) Effect of various patient positions on endotracheal tube cuff pressure after adult cardiac surgery. Res Cardiovasc Med 6(4): pp. 34-38.

19. Spooner AJ, Corley A, Sharpe NA, et al. (2014) Head-of-bed elevation improves end-expiratory lung volumes in mechanically ventilated subjects: a prospective observational study. Respir Care 59(10): pp. 1583-1589.

20. Martinez BP, Marques TI, Santos DR, et al. (2015) Influence of different degrees of head elevation on respiratory mechanics in mechanically ventilated patients. Rev Bras Ter Intensiva 27(4): pp. 347-52.

21. Sultan $P$, Carvalho B, Rose BO, et al. (2011) Endotracheal tube cuff pressure monitoring: a review of the evidence. J PerioperPract 21(11): pp. 379-386.

22. Khan MU, Khokar R, Qureshi S, et al. (2016) Measurement of endotracheal tube cuff pressure: instrumental versus conventional method. Saudi J Anaesth 10(4): pp. 428-431.

23. Cornejo RA, Diaz JC, Tobar EA, et al. (2013) Effects of prone positioning on lung protection in patients with acute respiratory distress syndrome. Am J Respir Crit Care Med 188(4): pp. 440448.

24. Ziyaeifard M, Ferasatkish R, Alizadehasl A, et al. (2017) Effect of various patient positions on endotracheal tube cuff pressure after adult cardiac surgery. Res Cardiovasc Med 6(4): pp. 34-38.

25. Letvin A, Kremer P, Silver PC, et al. (2018) Frequent Versus Infrequent Monitoring of Endotracheal Tube Cuff Pressures. Respir Care 63(5): pp. 495-501.

26. Sharifi A, Khatoni A, Rezaei M (2014) Is there a relationship between core body temperature and changes of endotracheal tube cuff pressure?. |Iranian J Crit Care Nurs 7(2): pp. 102-109.

27. IEikhar IH, Donley MA, Owens WB (2015) Prone positioning in acute respiratory distress syndrome. Critical Care Medicine 43(2): e55-6.

28. Niu T, Lv C, Yi G, et al. (2018) Therapeutic Effect of Medical Ozone on Lumbar Disc Herniation. Med Sci Monit 24(2): 19621969.
29. Cirovic S, Walsh C, Fraser WD, et al. (2003) The effect of posture and positive pressure breathing on the hemodynamics of the internal jugular vein. Aviat Space Environ Med 74(2): pp. 125-131.

30. Ezhevskaya AA, Mlyavykh SG, Anderson DG (2013) Spine. 38(15): 1324-1330.

31. Dziewas R, L€ udemann P (2002) Hypoglossal nerve palsy as complication of oral intubation, bronchoscopy and use of the laryngeal mask airway. Eur Neurol 47(4): 239-243.

32. Enersen, Ole Daniel. "Trendelenburg's position". Whonamedit.com Retrieved 2009-03-04.

33. Lore, Marybeth (2017) Umbilical Cord Prolapse and Other Cord Emergencies. The Global Library of Women's Medicine.

34. Farber SJ, Saheb-Al-Zamani M, Zieske L, et al. (2013) Peripheral nerve injury after local anesthetic injection. Anesth Analg 117(3): pp. 731-739.

35. Liu SS, YaDeau JT, Shaw PM, et al. (2011) Incidence of unintentional intraneural injection and postoperative neurological complications with ultrasound-guided interscalene and supraclavicular nerve blocks. Anaesthesia 66(3): pp. 168174.

36. Jacob AK, Mantilla CB, Sviggum HP, et al. (2011) Perioperative nerve injury after total hip arthroplasty. Anesthesiology 115(12): pp. 1172-1163.

37. Neal JM (2016) Ultrasound-guided regional anesthesia and patient safety: An evidence based analysis. Reg Anesth Pain Med 41(2): pp. s59-67.

38. Royal College of Anaesthetists. Patient Information Leaflet 13: Nerve damage associated with peripheral nerve block. https://www.rcoa.ac.uk/system/files/13-NerveDamagePe

39. Sultan P, Carvalho B, Rose BO, et al. (2011) Endotracheal tube cuff pressure monitoring: a review of the evidence. J PerioperPract 21(11): pp. 379-386.

40. Sardesai A, French J, Pawa A (2015) Patient consent for peripheral nerve blocks RA-UK. http://www.ra-uk.org/

41. Gadsden JC, Choi JJ, Lin E, et al. (2014) Opening injection pressure consistently detects needle-nerve contact during ultasound-guided interscalene brachial plexus block. Anesthesiol 120(5): pp. 1246-1253.

42. Maser R, Steenkiste A, Dorman J, et al. (2009) Epidemiological correlates of diabetic neuropathy: Report from Pittsburgh epidemiology of diabetes complications study. Diabetes 38(11): 1456-1461.

43. Whitlock EL, Brenner MJ, Fox IK, et al. (2010) Ropivacaineinduced peripheral nerve injection injury in the rodent model. Anes Analg 111(1): 214-220.

44. Mekis D, Kamenik M (2010) Influence of body position on hemodynamics in patients with ischemic heart disease undergoing cardiac surgery. Wien Klin Wochenschr 122(2): pp. 59-62.

45. Buys YM, Alasbali T, Jin YP, et al. (2010) Effect of sleeping in a head-up position on intraocular pressure in patients with glaucoma. Ophthalmology 117(7): pp. 1348-1351. 